\title{
Composite poplars: a novel tool for ectomycorrhizal research
}

\author{
Dimitri Neb $^{1} \cdot$ Arpita Das $^{1} \cdot$ Annette Hintelmann ${ }^{1} \cdot$ Uwe Nehls $^{1}[$
}

Received: 17 March 2017 / Accepted: 4 October 2017 / Published online: 23 October 2017

(C) The Author(s) 2017. This article is an open access publication

\begin{abstract}
Key Message Composite poplars were used for ectomycorrhiza formation. Structurally normal mycorrhizas of transgenic roots revealed better fungal sugar support. Targeting fluorescent proteins to peroxisomes allowed easy in planta visualization of successful transformation. Abstract A bottle neck in ectomycorrhizal research is the time demand for generation of transgenic plants. An alternative strategy for such root-centered research might be the formation of the so-called composite plants, where transgenic roots are formed by non-transgenic shoots. We have developed an Agrobacterium rhizogenes-mediated root transformation protocol using axenic Populus tremula $\times$ tremuloides and P. tremula $\times$ alba cuttings. When comparing four different bacterial strains, A. rhizogenes K599 turned out to be the most suitable for poplar transformation. Transgenic roots revealed only minor hairy root phenotype when plants were grown on agar plates with synthetic growth medium in the absence of a sugar source. When using different ectomycorrhizal fungi, formation of ectomycorrhizas by transgenic roots of composite poplars was not affected and mycorrhizas were anatomically indistinguishable from mycorrhizas of non-transgenic roots. Elevated trehalose content and marker gene expression, however, pointed towards somewhat better fungal carbon nutrition in ectomycorrhizas of transgenic compared to non-transgenic roots. Cell wall autofluorescence of poplar fine roots is an issue that can limit the use of fluorescent proteins as visual markers for
\end{abstract}

Communicated by Howard S. Judelson.

Uwe Nehls

nehls@uni-bremen.de

1 Faculty 2, Biology/Chemistry, Botany, University of Bremen, Leobener Str. 2, 28359 Bremen, Germany in planta analysis, especially after ectomycorrhiza formation. By targeting marker proteins to peroxisomes, sensitive fluorescence detection, easily distinguishable from cell wall autofluorescence, was obtained for both poplar fine roots and ectomycorrhizas.

Keywords Agrobacterium - Plant transformation .

Composite poplars $\cdot$ Ectomycorrhiza $\cdot$ Fluorescent proteins

\section{Introduction}

Due to a frequently nutrient limited environment combined with extended seasonality, boreal and temperate forests dominate large parts of the northern hemisphere. To guarantee optimal function of these ecosystems, the mutualistic interaction of tree roots with ectomycorrhizal (ECM) fungi is essential (Smith and Read 2008). In this type of symbiosis, the fungal partner provides soil-based water and mineral nutrients, while the plant serves the basic carbohydrates from photosynthesis.

Due to its rapid growth and easily handling properties under laboratory and green house conditions, together with the establishment of molecular tools (Holsters et al. 1978) and Agrobacterium tumefaciens-based transformation protocols (e.g., Nowak et al. 2004; Ohmiya et al. 2003; Park et al. 2009; Zhang et al. 2014), poplar became a favored model for ectomycorrhizal research. With respect to ectomycorrhizal plant colonization, a (limited) number of laboratory- and field-based (e.g., Stefani et al. 2009; Danielsen et al. 2013) studies revealed no general impact of transgenic properties on symbiosis. However, due to the time request for generation and propagation of transgenic plants, which usually lasts for more than a year (Alpizar et al. 2006; Hampp et al. 
1996), generation of transgenic poplars is still a bottleneck, limiting ECM research.

With the establishment of the so-called composite plants, where transgenic roots emerge from non-transgenic shoots after Agrobacterium rhizogenes infection, Hansen et al. (1989) established an alternative strategy for plant transformation. Generation of transgenic roots is much faster (a few weeks) than the conventional transformation (several month) for many plants (Veena and Taylor 2007). However, transgenic root induction by A. rhizogenes also has some drawbacks. Most obviously, generation of transgenic roots by non-transgenic shoots limits this approach mainly to rootcentered questions, even if some examples of above-ground gene silencing in composite plants by dsRNA expression are found in the literature (Veena and Taylor 2007). A restriction of transgenic properties to roots has, however, also advantages. Interference with gene function in other plant organs is omitted in most cases.

A second difference to the conventional A.tumefaciensbased transgenic plants is that roots of composite plants frequently reveal a so-called hairy root phenotype, which is characterized by the extensive development of root hairs, and a reduced gravity response (Veena and Taylor 2007). Responsible for hairy root characteristics is the requirement of non-disarmed bacterial strains for root induction. These strains still contain specific Ri plasmids that harbor distinct T-DNA regions, which are transmitted together with a second T-DNA of interest (located on a shuttle vector) into plant cells (An 1985; Collier et al. 2005; Mankin et al. 2007). These Ri-plasmid located T-DNAs contain genes that affect either plant auxin response or lead to increased auxin biosynthesis (Cardarelli et al. 1987). Thereby they cause the induction of shoot-derived transgenic roots but also the socalled hairy root phenotype.

Despite these limitations, numerous successful applications of composite plants both in applied (Srivastava and Srivastava 2007; Banerjee et al. 2017) and basic research (see below) are found in the literature. A. rhizogenes-based approaches were used for gene expression analysis at cell type resolution (e.g., Ron et al. 2014) or investigations of mechanisms of gene regulation (e.g., Kim et al. 2011). Composite plants were used in particular to investigate root development (e.g., Kereszt et al. 2007), especially in response to biotic interaction with nematodes (e.g., Wubben et al. 2009), bacteria (e.g., Hirsch et al. 2009), or fungi (e.g., Mrosk et al. 2009).

To elucidate the potential of composite plants in ectomycorrhizal research and to speed up molecular and functional research of this type of symbiosis, we have developed an $A$. rhizogenes-based protocol for a fast generation of composite poplars and investigated the ability of transgenic roots to form functional ectomycorrhizas. A. rhizogenes strains that are commonly used for plant transformation differ in their Ri-plasmid and can be grouped by the type of opines (agropine type, mannopine type, cucumopine type, and mikimopine type) produced by infected plants after T-DNA integration (Veena and Taylor 2007). Which bacterial strain is suited best for the generation of composite plants has to be investigated individually for any plant species. Therefore, we compared four A. rhizogenes subtypes for their potential to induce transgenic poplar roots. To overcome problems with autofluorescence of poplar roots and in particular of ectomycorrhizas, we tested a peroxisome-targeted fluorescent protein approach to follow root transformation in vivo. Properties of ectomycorrhizas formed by transgenic roots of composite plants were analyzed in terms of anatomy, plant and fungal sugar content (as indicator for mycorrhizal physiology; Hampp et al. 1995, 2000), as well as gene expression. Here, we used an ectomycorrhiza-induced poplar SWEET gene as molecular marker for the formation of functional ectomycorrhizas (Nehls and Bodendiek 2012). SWEET proteins were characterized as sugar facilitators and are supposed to function as sugar efflux carriers in biotrophic interactions (Chen et al. 2010; Eom et al. 2015), including ectomycorrhizas (Nehls and Bodendiek 2012).

\section{Materials and methods}

\section{Biological material}

Populus tremula $\times$ tremuloides (clone T89), P. tremula $\times$ alba (INRA clone no. 717.1B4), and P. trichocarpa (Nisqually 1) plants were grown under sterile conditions on MS6 (Murashige and Skoog 1962) or McCown woody plant (Lloyd and McCown 1980; only P. trichocarpa) medium (both obtained from Duchefa Biochemie, Haarlen, The Netherlands); in a growth chamber $\left(18{ }^{\circ} \mathrm{C}, 16 \mathrm{~h}, 80 \mu \mathrm{mol}\right.$ photons $\mathrm{m}^{-2} \mathrm{~s}^{-1}$ illumination). For propagation of the plants, shoot cuttings were used.

The following A. rhizogenes strains were analyzed for their capability to form poplar composite plants: 1724, a mikimopine strain (Shiomi et al. 1987); K599, a cucumopine strain (Daimon et al. 1990); 8196, a mannopine strain (Hansen et al. 1991); and 15834, an agropine strain (Veena and Taylor 2007). All A. rhizogenes strains were grown on solid CPY medium at $28{ }^{\circ} \mathrm{C}$, supplemented with $50 \mathrm{mg} \mathrm{l}^{-1}$ kanamycin (Duchefa Biochemie) if necessary.

\section{Generation of composite poplars and ectomycorrhiza synthesis}

Agrobacterium rhizogenes strains were transformed according to (Holsters et al. 1978) and grown on CPY agar plates supplemented with Kanamycin $(50 \mathrm{mg} / \mathrm{l})$ for up to 2 days at $28{ }^{\circ} \mathrm{C}$ until colonies appeared. 
The cut surface of about 4-week-old sterile $P$. tremula $\times$ alba cuttings was dipped into a transformed agrobacterial colony grown on agar plates, poked about $4 \mathrm{~mm}$ deep into MS agar in a Petri dish, and incubated at $22{ }^{\circ} \mathrm{C}$ with $12 \mu \mathrm{mol}$ photons $\mathrm{m}^{-2} \mathrm{~s}^{-1}$ illumination $(16 \mathrm{~h}$ day-night rhythm) for 3 days. The cuttings were then transferred to fresh MS6 agar plates supplemented with carbenicilin $(1.18 \mathrm{mM}$, Duchefa Biochemie) and cefotaxime $(0.52 \mathrm{mM}$, Duchefa Biochemie) to restrain agrobacterial growth and cultivated as described before until transgenic roots reached a length of about $1-2 \mathrm{~cm}$. These plants and non-inoculated control plants were further used for ectomycorrhizal formation under axenic conditions according to Hampp et al. (1996) with some modifications (see below) using Amanita muscaria, Laccaria bicolor, Paxillus involutus, or Pisolithus tinctorius as ECM fungal partner.

For mycorrhization, fungal mycelia were pregrown on modified MMN agar plates (Kottke et al. 1987) containing $50 \mathrm{mM}$ glucose as sole carbon source at $18{ }^{\circ} \mathrm{C}$ for about 6 weeks. Six pieces of the growing mycelial front with about $5 \mathrm{~mm}$ edge length were transferred to fresh cellophane covered MMN agar plates containing $10 \mathrm{mM}$ glucose and incubated at $18{ }^{\circ} \mathrm{C}$ in the dark for about 4 weeks. When the mycelium around the agar plugs reached a diameter of 2-3 cm, the membrane was transferred to fresh MMN medium having reduced nitrogen content $(0.4 \mathrm{mM})$ and no carbon source. Poplar composite plants were transferred to these agar plates, such that the root system was placed inside the petri dish next to the mycelium, while the shoot remained outside (Hampp et al. 1996). Petri dishes were sealed with Parafilm and silicon grease and kept in a vertical position in a miniature greenhouse which provided high humidity at $18{ }^{\circ} \mathrm{C}$. The root system was kept in dark by sheets of black paper covering the dishes, while the shoots were illuminated $\left(16 \mathrm{~h}\right.$ light-dark cycle and $80 \mu \mathrm{mol}$ photons $\left.\mathrm{m}^{-2} \mathrm{~s}^{-1}\right)$. Ectomycorrhizas were formed after about 2-3 months.

\section{Microscopic inspection}

Root formation of composite plants was followed by epifluorescence microscopy (Mz10F, Leica Microsystems, Wetzlar, Germany). Illumination was performed by UV light using a LQ-HXP 120 (Leistungselektronik JENA GmbH, Jena, Germany) as light source. The YFP filter set (excitation 510-520 nm, emission 540-560 nm) was used and images were taken using a video camera (DFC425 C, Leica).

Sections of non-infected fine roots and ectomycorrhizas were prepared using a vibratome (VT1000S, Leica). Fine roots and mycorrhizas were harvested using forceps (DuPont No. 5, Wilmington, USA) and embedded in $200 \mu \mathrm{l}$ of preheated $\left(60{ }^{\circ} \mathrm{C}\right) 4 \%$ water agarose. The root material was quickly transferred into a pressure vial (Dobner 2003) to remove air bubbles in the fungal mycelium surrounding the infected fine root (fungal mantle) and kept there until the agarose was completely solidified. Upper and the lower parts of agarose blocks were cut prior to fixation on the carrier using preheated agarose. About $100 \mu \mathrm{m}$ thick cross and longitudinal sections were generated.

YFP expression was visualized in entire roots/mycorrhizas as well as in sections by confocal laser scanning microscopy (LSM 780, Carl Zeiss, Göttingen, Germany) using an argon laser (488 and $514 \mathrm{~nm}$ ) with a primary beam splitter mirrors $(488 / 514 \mathrm{~nm}$ ) and a band-pass detector (sYFP detection window: $520-550 \mathrm{~nm}$ ).

\section{Analysis of gene expression by quantitative RT-PCR (q-PCR)}

Total RNA was isolated from P. tremula $\times$ albalA. muscaria ectomycorrhizal or non-mycorrhizal fine roots using the NucleoSpin RNA Plant kit (Macherey-Nagel, Düren, Germany) according to the manufacturer's instructions (including DNAse treatment). RNA integrity was proven by agarose gel electrophoresis and RNA content was quantified by photometry and image analysis. Aliquots containing $60 \mathrm{ng}$ of total RNA were used for first-strand cDNA synthesis in a total volume of $20 \mu \mathrm{l}$, containing $50 \mathrm{pmol}$ oligo-d(T)18-primer (Eurofins-MWG-Operon, Ebersberg, Germany), $0.5 \mu 1$ RNAse inhibitor (RiboLock ${ }^{\mathrm{TM}}$ RNAse, $40 \mathrm{U} / \mu \mathrm{l}$, Thermo Fisher Scientific), and $200 \mathrm{U}$ Superscript II RNAse H-Reverse Transcriptase (Thermo Fisher Scientific) according to the manufacturer's instructions. After synthesis, $30 \mu \mathrm{l}$ of $5 \mathrm{mM}$ Tris/ $\mathrm{HCl}$, $\mathrm{pH} 8$ were added, and aliquots were stored at $-80^{\circ} \mathrm{C}$.

PtaSWEET1-specific primers (TTGGGCTACTTGGTG GTGACC, GATACCCATCTGCATTGACTTAAC) were designed, such that the reverse primer was located within the non-coding $3^{\prime}$ region. As references, gene-specific primers of ubiquitin (Brunner et al. 2004) or actin (Langer et al. 2004), which have been extensively used in previous publications (Selle et al. 2005; Ehlting et al. 2007; Escalante-Pérez et al. 2008; Willmann et al. 2014), were used as reference gene to calibrate the mRNA content.

Quantitative PCR was performed using $10 \mu \mathrm{l}$ Q-PCRMaster mix (Thermo Fisher Scientific), $0.5 \mu \mathrm{l}$ cDNA, and 10 pmol of each primer in a Light Cycler 480 System (Roche, Basel, Switzerland). PCR was always performed in triplicate.

Two independent cDNA synthesis reactions of two different root and mycorrhizal batches (obtained from at least four independent plants) were used for analysis of PttSweet 1 c expression in roots of control and composite plants. For determination of PCR efficiency, dilution series of each gene were prepared and used as template. The corresponding PCR efficiencies were calculated by the Light Cycler 480 software package (Version 1.5, Roche). 


\section{Analysis of soluble sugars}

Soluble sugars were quantified according to Schaeffer et al. (1995) with some modifications (see below). Freshly isolated mycorrhizas of transgenic and non-transgenic plants (two batches of six plants each) were isolated from agar plates, pooled and snap frozen in liquid nitrogen. Grinding to a fine powder was performed under liquid nitrogen using a pestle and a $1.5 \mathrm{ml}$ Eppendorf tube as morter. The powder was freeze dried under vacuum and aliquots of about $0.5 \mathrm{mg}$ were transferred into fresh $1.5 \mathrm{ml}$ Eppendorf tubes in a conditioned room ( $40 \%$ humidity, $\left.18{ }^{\circ} \mathrm{C}\right)$. Extraction of soluble sugars was performed with a total volume of $400 \mu \mathrm{l}$ methanol using a pestle and a $1.5 \mathrm{ml}$ Eppendorf tube as morter. After incubation of the suspensions for $1 \mathrm{~h}$ at $60^{\circ} \mathrm{C}$, the samples were centrifuged $\left(50 \mathrm{~min}\right.$ at $20^{\circ} \mathrm{C}$ and $20,000 \mathrm{~g}$ ) and $320 \mu \mathrm{l}$ of the supernatant were transferred into fresh $1.5 \mathrm{ml}$ tubes. Methanol was evaporated under vacuum, soluble sugars were dissolved in $90 \mu \mathrm{l}$ higly pure water, and aliquots were applied to a Dionex DX 500-liquid chromatography system (Thermo Fisher Scientific GmbH, Dreieich, Germany) containing a CarboPack PA10 (Thermo Fisher Scientific). Sugar quantification was performed using a Pulsed Amperometric Detector (ED40, Thermo Fisher Scientific) and calibration standards.

\section{Results}

\section{Transgenic root induction by $A$. rhizogenes}

We have tested four different $A$. rhizogenes strains for their capacity to induce and transform shoot based roots using sterile, about 1-month-old $P$. tremula $\times$ tremuloides (data not shown) and $P$. tremula $\times$ alba cuttings. Both hybrid poplars revealed similar results. Except for the agropine A. rhizogenes strain 15834 that revealed a kinetic similar to that of the water control, root formation was retarded when plants were inoculated with agrobacteria (Fig. 1). Especially, the mikimopine strain 1724 revealed a large proportion of plants $(85 \%)$, where no roots were formed even after 7 weeks. For plants, where roots were formed after seven weeks of inoculation, the root number per plant did not differ significantly between water control $(3.85 \pm 2.1)$ and plants inoculated with the A. rhizogenes strains $1724(4.67 \pm 2.52)$ or 8196 $(5.56 \pm 3.51)$ (Fig. 2). In contrast, plants inoculated with the cucumopine strain K599 revealed a slight $(6.37 \pm 2.85)$ but highly significant increase in root number, while those inoculated with 15834 revealed many more $(18.06 \pm 7.74)$ roots per plant. Except for control and 15834 (agropine strain) mediated composite plants (data not shown), poplar cuttings inoculated with K599 (cucumopine strain), 8196 (mannopine strain), and 1724 (mikimopine strain) developed

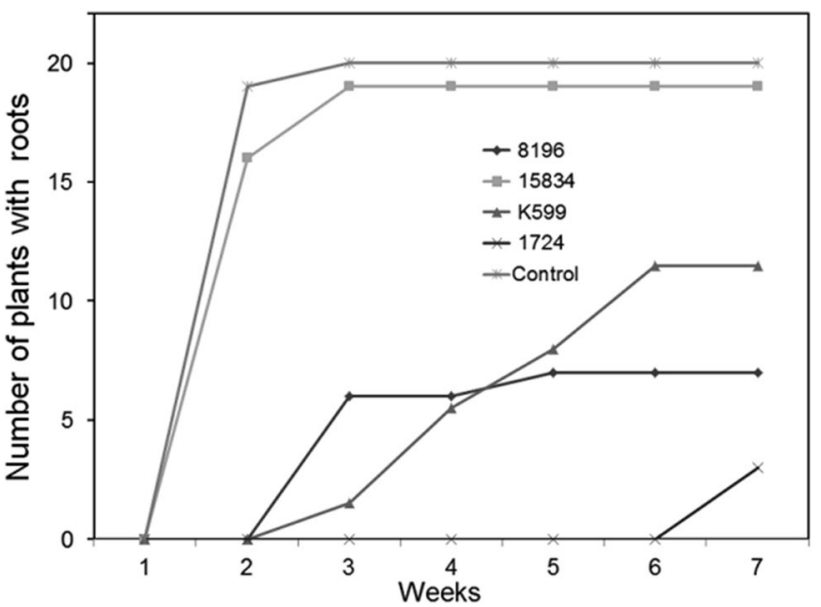

Fig. 1 Kinetics of root formation of poplar cuttings inoculated with different $A$. rhizogenes strains. Root formation by poplar cuttings inoculated with one of the following A. rhizogenes strains 15834, K599, 8196, 1724, or water (control) was followed over a time period of 7 weeks. Shown is the percentage of plants that had formed at least a single root at the given timepoint. A total of 20 cuttings each were used for the analysis

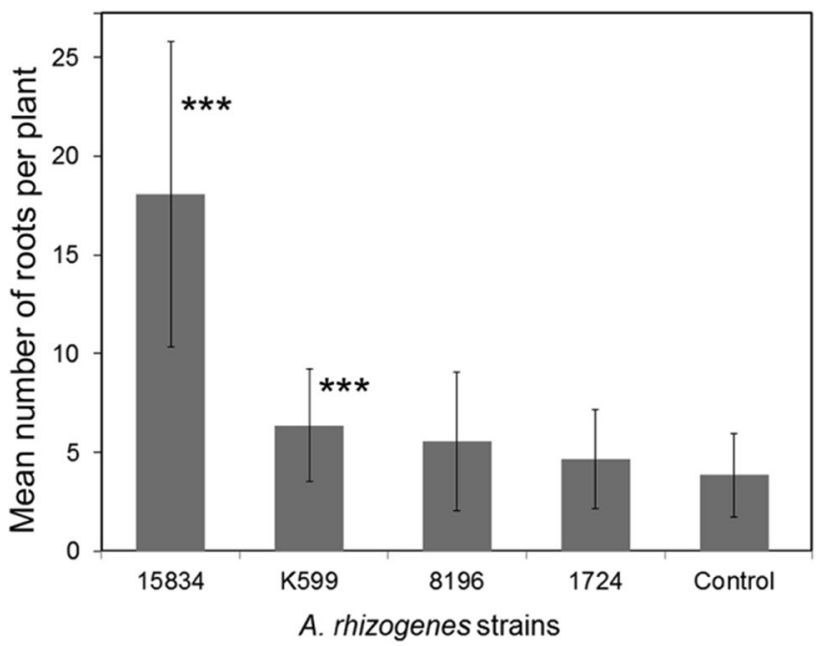

Fig. 2 Mean number of roots formed per plant. Plants from Fig. 1 were assessed for the number of roots that were formed per poplar cutting after 7 weeks of inoculation with the respective agrobacterial strain or distilled water (control). Plants that did not form roots at all were omitted from this analysis. Shown are mean values and standard errors. The number of roots per plant differed significantly (student $t$ test) from that of control plants (20 plants) for 15834 ( $p$ value: $2.8 \times 10^{-9}, 19$ plants $)$ and $\mathrm{K} 599\left(8.13 \times 10^{-4}, 12\right.$ plants $)$ but not for 8196 ( $p$ value: $0.132,7$ plants) and 1724 ( $p$ value: $0.546,3$ plants)

microcalli at the infected shoot surface prior to root formation (an example for K599 is shown in Fig. 3).

To visualize Agrobacterium-mediated stable T-DNA transmission from a binary vector into the plant genome, all agrobacterial strains were transformed with the binary vector pBIN19-YFPPTS1 (Nowak et al. 2004) prior to plant 
Fig. 3 Microcallus formation at the shoot surface of cuttings inoculated with A. rhizogenes strain K599. The formation of microcalli at the surface of $P$. tremula $\times$ alba cuttings was visualized 3 weeks after inoculation with pBIN19-YFPPTS1 transformed A. rhizogenes strain K599 by microscopy: A transmission light, B UV light (YFP filter set). Labelled by an arrow is a transgenic microcallus from which root formation is initiated
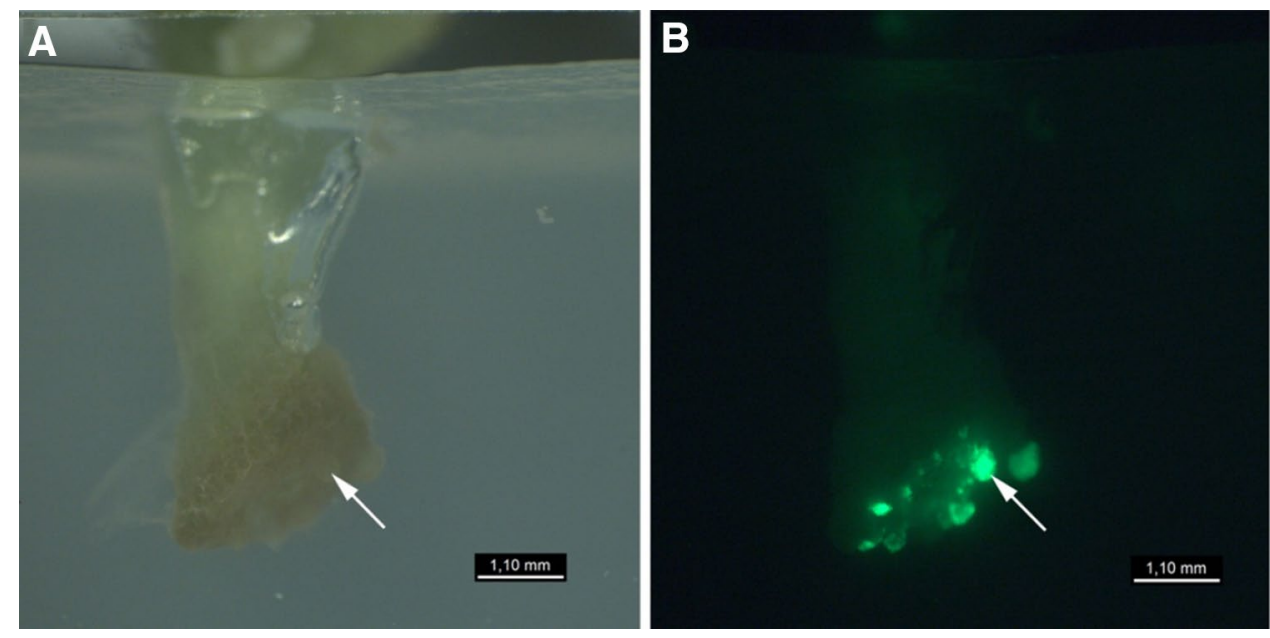

infection. This vector contains a marker cassette that allows a strong, constitutive in planta expression of a peroxisometargeted yellow fluorescent protein (YFP) as a consequence of successful plant transformation. Out of the four tested agrobacterial strains, only K599 reproducibly allowed easy in planta YFP signal detection by epifluorescence microscopy for both hybrid poplars (in Fig. 3B an example for P. tremula $\times$ alba is shown), while for $P$. trichocarpa, no fluorescent roots were obtained at all. Because inoculation of poplar cuttings with the agrobacterial strain K599 showed furthermore only minor retardation in root formation and a weak tendency for the hairy root phenotype (e.g., formation of a moderate increased root number), this strain was selected for further analysis.

\section{Induction and growth properties of roots on sucrose containing medium}

The standard rooting medium for poplar cuttings contains $1 \%$ sucrose, which has been shown to be a potent root morphogen in Arabidopsis. We have, therefore, compared formation and growth properties of roots on sucrose containing or free agar plates using non-inoculated (control) and K599 inoculated cuttings.

When control cuttings were incubated in sucrosefree medium, $67 \%$ revealed initial root formation after one week, while only $17 \%$ of the cuttings started rooting on sugar containing medium (Fig. 4). However, all control plants were rooted after 4 weeks, independently on whether they were grown on sucrose containing or free medium. In contrast, cuttings inoculated with K599 showed no obvious difference in root formation kinetics on sucrose containing or sucrose-free agar (Fig. 4). Furthermore, K599-inoculated poplars revealed a slightly larger number of rooted cuttings after 8 weeks of growth in the absence of sucrose (Fig. 4).

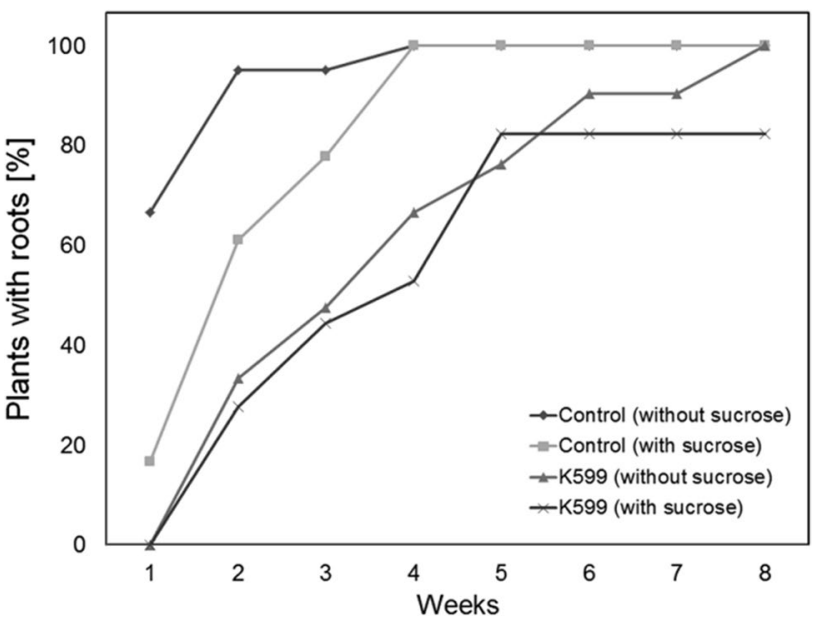

Fig. 4 Effect of sucrose on the root formation of poplar cuttings inoculated with A. rhizogenes strain K599 or water. Root formation was assessed once a week for a period of 8 weeks after inoculation of poplar cuttings ( $n=20$, each) with the A. rhizogenes strain K599 or water (as control). Shown is the percentage of cutting that revealed at least one root per plant at a given timepoint

When grown on sucrose containing medium, control plants showed a highly significant $(p=0.0004)$ larger root number after 8 weeks $(9.6 \pm 3.3$ versus $6.2 \pm 1.9)$, while K599 treated cuttings revealed only a not significant $(p=0.38)$ tendency for a larger root number $(7.4 \pm 4.2$ versus $5.7 \pm 2.3)$.

Sucrose also had a severe impact on root branching for both control- and K599-treated cuttings. The presence of sucrose in the growth medium significantly $\left(p=1.7 \times 10^{-9}\right.$ and $7.32 \times 10^{-6}$, respectively) elevated the number of branches per root (control cuttings: $11 \pm 7.1$ versus $0.5 \pm 0.8$; K599-treated cuttings: $8.3 \pm 7$ versus $2.0 \pm 2.4$ ). 


\section{Root cotransformation efficiency}

To determine the efficiency by which the binary vector located T-DNA was transmitted into shoot-derived poplar roots, cuttings were inoculated with transgenic K599 harboring a peroxisome-targeted YFP under the control of a constitutive promoter. Roots were investigated after 8 weeks of inoculation for YFP expression by epifluorescence microscopy. 50 out of a total of 55 composite plants showed at least one root that expressed the YFP marker and $88.1 \%$ of all roots that were formed showed YFP expression, demonstrating the success of the composite plant strategy to obtain transgenic poplar roots. In addition to pBin19 (Bevan 1984), we have also tested binary vectors with pGreenII (Hellens et al. 2000) background for K599-based poplar transformation, revealing similar transformation efficiencies (data not shown).
Cell wall autofluorescence of poplar roots may interfere with fluorescent protein signal detection

Strong cell wall autofluorescence was observed in nonmycorrhized (Fig. 5) and mycorrhized (Fig. 8) poplar fine roots exposed to laser intensities of 5\% power and more. This autofluorescence covered a wide emission spectrum (500-650 nm), independent on whether 458, 488, or $561 \mathrm{~nm}$ laser lines are used for excitation. For non-infected fine roots, autofluorescence became much weaker at laser intensities below $2 \%$, allowing a better discrimination of the specific YFP signal (Fig. 6A, B). However, in ectomycorrhizas, cell wall autofluorescence was much stronger (especially in the Hartig net area, Fig. 8). Because some peroxisomes are always located in a given distance to the cell wall, a clear YFP signal recognition was still feasible (yellow dots in Fig. 8).

No obvious chimera roots, revealing fluorescent and nonfluorescent branches, were ever observed in poplar composite plants (data not shown). Furthermore, cross sections along transgenic roots (from tip to base) indicated YFP fluorescent peroxisomes in cells of all root tissues (rhizodermis,
Fig. 5 Autofluorescence of poplar fine roots. Radial sections of non-transgenic poplar fine roots were obtained from fresh root material and analyzed by laser scanning microscopy (excitation: argon laser, $488 \mathrm{~nm}$, $10 \%$ power). Shown are (in false color) the YFP channel (A, detection range $510-560 \mathrm{~nm})$, the ds red channel $(\mathbf{B}$, detection range $560-650 \mathrm{~nm}$ ), the transmission light channel $(\mathbf{C}$, TMP), and an overlay of the three images (D). (Color figure online)
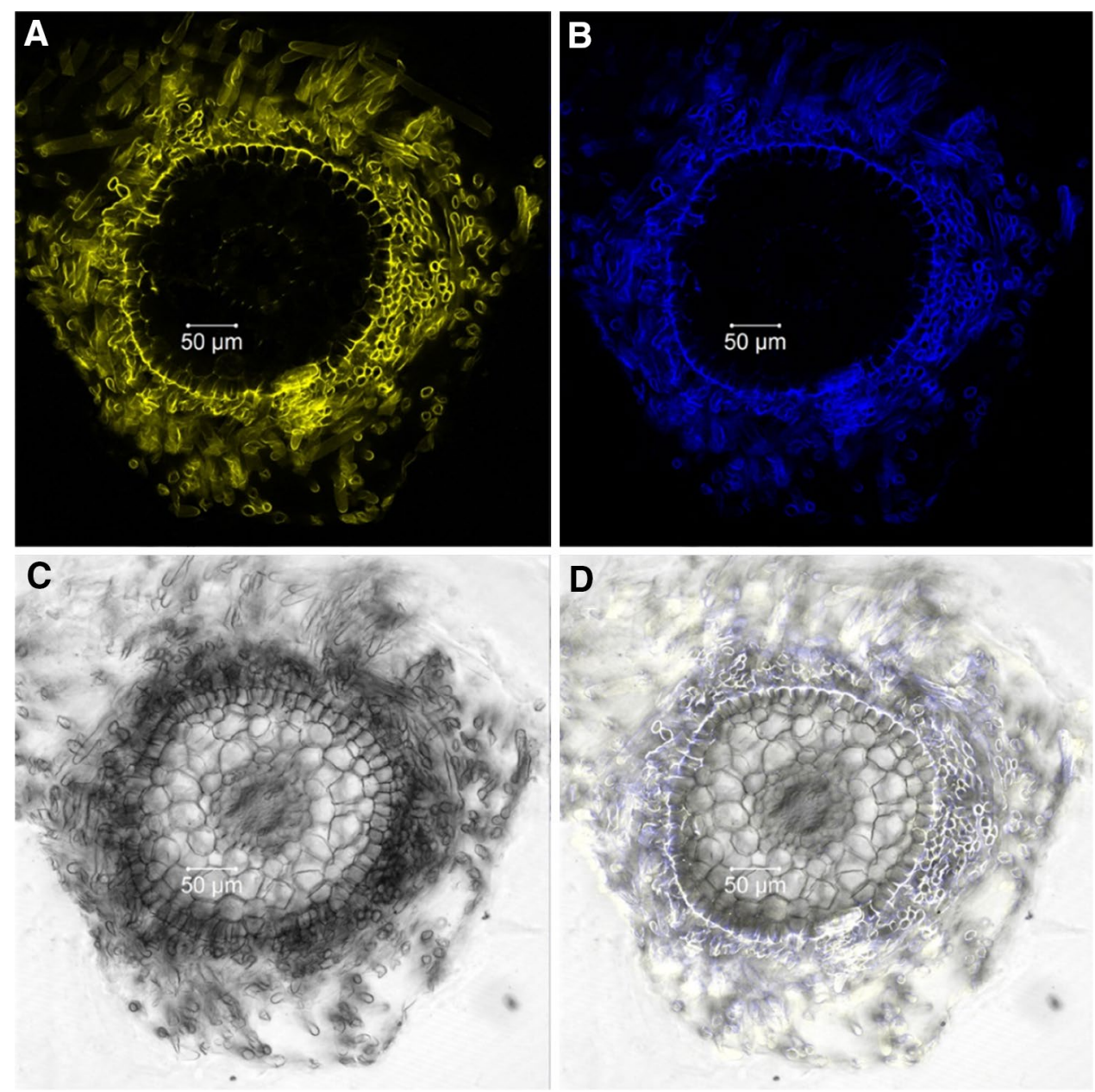

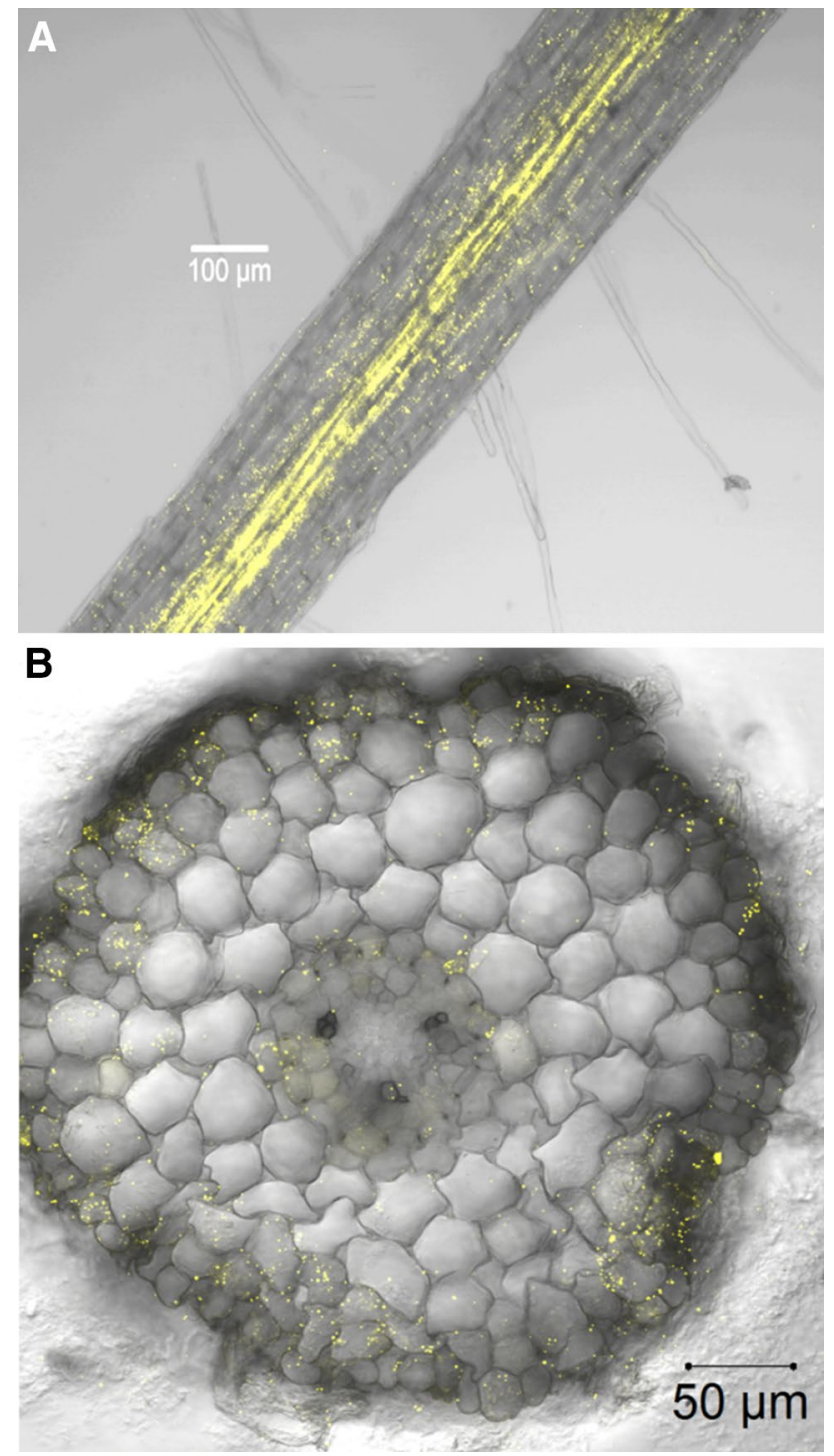

Fig. 6 Peroxisome located YFP fluorescence of a transgenic root mediated by A. rhizogenes transformation. 6-week-old A. rhizogenes (K599) mediated transgenic roots of composite $P$. tremula $\times$ alba plants were investigated for peroxisome-targeted yellow fluorescent protein distribution. Whole mounts as well as cross sections were visualized by laser scanning microscopy (excitation: argon laser, $488 \mathrm{~nm}, 2 \%$ power). Peroxisomes are shown in yellow (false colors). Images are overlays of the YFP channel (detection range 510$560 \mathrm{~nm}$ ) and the transmission light channel. Shown are in $\mathbf{A}$ a whole mount view and in $\mathbf{B}$ a cross section of an YFP expressing transgenic poplar root. (Color figure online)

cortex, endodermis, stele; an example of a cross section is shown in Fig. 6B).

\section{Ectomycorrhiza formation and function}

Agrobacterium rhizogenes-mediated transformed poplar roots were able to form ectomycorrhizas with A. muscaria (Fig. 7), L. bicolor, P. involutus, and P. tinctorius (data not

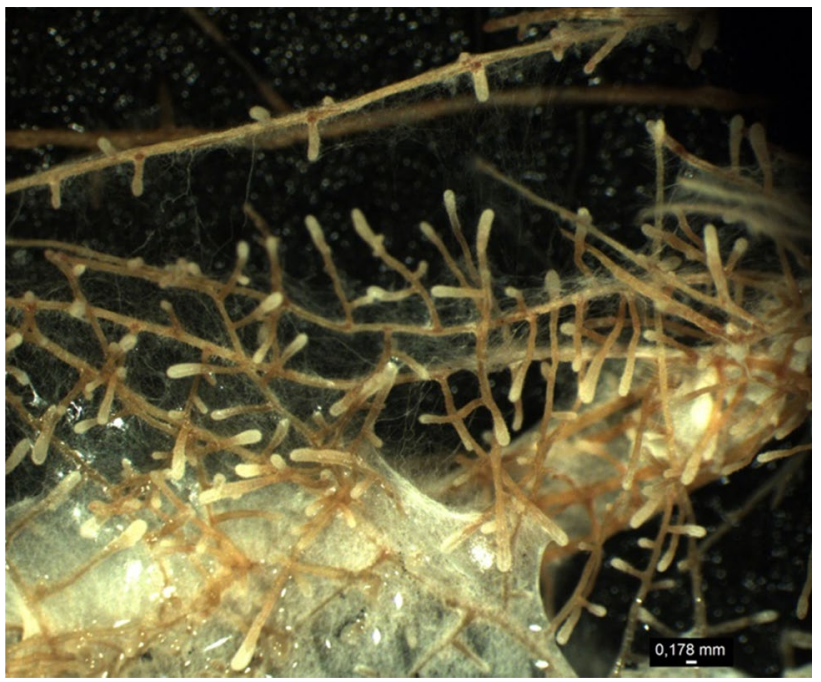

Fig. 7 Typical ectomycorrhizas formed by roots of a transgenic composite poplar. $P$. tremula $\times$ alba cuttings were inoculated with transgenic A. rhizogenes (K599) expressing a peroxisome-targeted YFP under the control of a constitutive promoter. Composite poplar plants were used for inoculation with A. muscaria as ectomycorrhizal fungal partner when newly formed roots reached a length of about $2 \mathrm{~cm}$. Shown is a section of the root system of a composite plant after 3-month of inoculation

shown) under sterile conditions in a time frame of about 2-3 months after inoculation. Longitudinal sections through ectomycorrhizal roots (Fig. 8A, B) revealed typical mycorrhizal structures with elongated rhizodermal cells in the Hartig net area and a characteristic fungal sheath, composed of several layers of fungal mycelium covering the infected fine root (Fig. 8B).

To test the functionality of ectomycorrhizas formed by the transgenic roots, two approaches were followed: (a) determination of plant- and fungus-specific sugars and (b) transcript levels of the ectomycorrhiza-specific induced poplar gene PtaSWEETI.

(a) Sucrose (plant origin) and trehalose (fungal origin) contents of ectomycorrhizas of transgenic and nontransgenic poplar roots were analyzed by liquid chromatography. While no significant difference in sucrose content was observed, trehalose content was significant higher (about 24\%) in ectomycorrhizas of transgenic roots (Fig. 9).

(b) Ectomycorrhizal marker gene (PtaSWEET1) expression was analyzed by q-PCR. Similar to wild-type roots, an ectomycorrhiza-specific induction of PtaSWEET1 expression was also observed in mycorrhizas of transgenic composite plants (Fig. 10). Interestingly, like the fungal sugar content, PtaSWEETI transcript levels were also about $25 \%$ higher in mycorrhizas of transgenic roots.« 


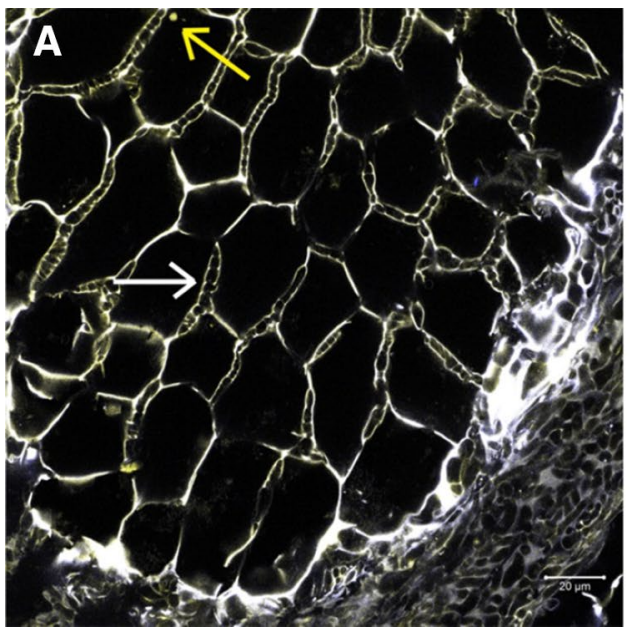

Fig. 8 Longitudinal sections through a typical ectomycorrhiza. Cell walls of fungal hyphae and root cells were visualized by their autofluorescence after illumination with an argon laser beam (488 nm, 10\% power). Shown are overlays of the YFP channel (in yellow, detection range 510-560 nm) and the ds Red channel (in blue, detection range 560-650 nm). Shown are longitudinal sections through A cortex layer

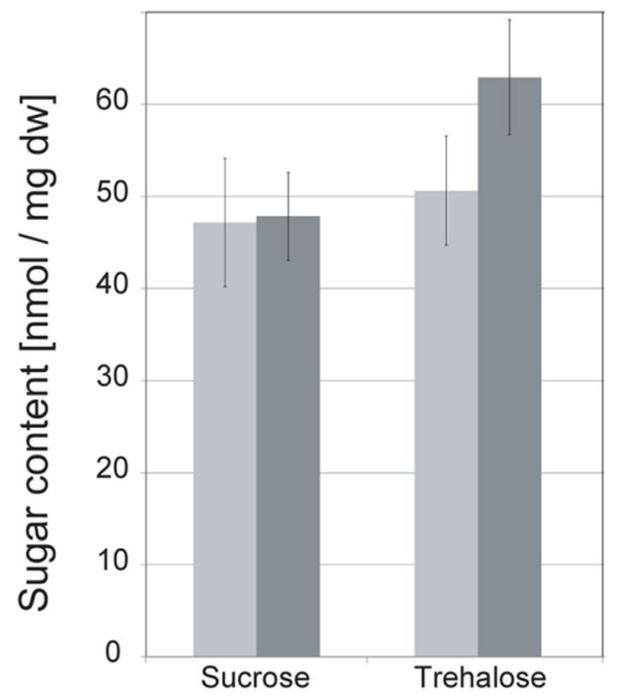

Fig. 9 Sugar content in mycorrhizas of transgenic and non-transgenic plants. Mycorrhizas were harvested from transgenic and nontransgenic roots of $P$. tremula $\times$ alba plants grown for about 3 months in Petri dishes with A. muscaria as ECM fungal partner. Shown is the sugar (trehalose, sucrose) content of mycorrhizas of non-transgenic (light gray) and transgenic (dark gray) roots in $\mathrm{nmol} / \mathrm{mg}$ dry weight. $P$ values comparing sugar content of mycorrhizas of transgenic and non-transgenic roots are as follows (Student's $t$ test): sucrose: $p=0.85$, trehalose: $p=0.006$

\section{Discussion}

Four different $A$. rhizogenes strains, belonging to different opine types, were analyzed for their suitability for poplar root transformation. Apart from the agropine type (strain

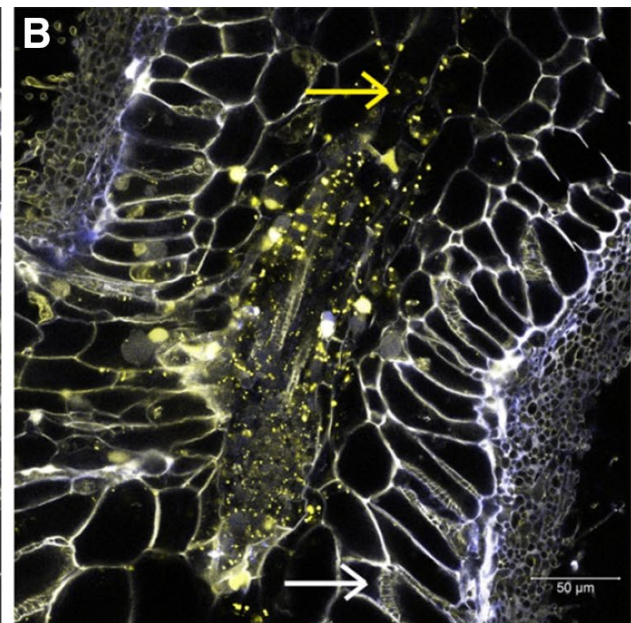

of an infected fine root and $\mathbf{B}$ deeper layer of another root at a lower magnification, where the central cylinder (yellow arrow) can be seen in addition to the Hartig net (white arrow) and the root cortex. Examples, where fungal hyphae can be easily visualized within the Hartig net are marked by white arrows. Yellow dots: peroxisome-targeted YFP (examples are indicated by yellow arrows). (Color figure online)

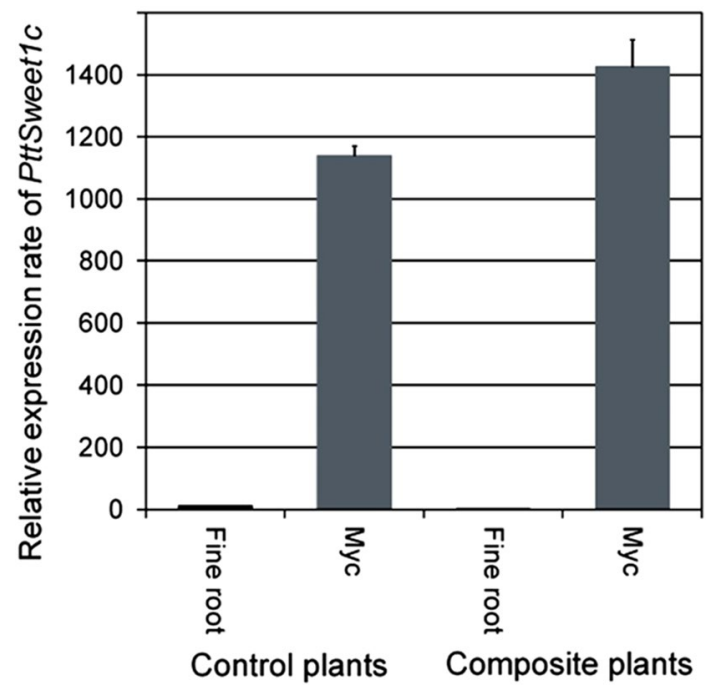

Fig. 10 PtaSWEET1 expression in ectomycorrhizas and non-mycorrhized fine roots of transgenic composite and non-transgenic control plants. Fine roots and mycorrhizas were harvested from transgenic composite and non-transgenic $P$. tremula $\times$ alba plants grown for about 3 months in Petri dishes in the presence or absence of $A$. muscaria as ECM fungal partner. First-strand cDNA (as template) together with gene-specific primers was used for expression analysis (quantitative RT-PCR). Shown are mean values and standard errors of CT ratios of PtaSWEET1 and ubiquitin (comparable results were obtained by using actin as reference)

15834), all other strains induced extended microcallus formation at the cut surface of poplar cuttings prior to rooting. As a consequence, retarded root formation was observed. Furthermore, microcallus formation complicated plant 
handling upon ectomycorrhiza synthesis as root harboring microcalli were fragile. Nevertheless, even when forming microcalli, strain K599 turned out to be the most suitable for a reproducible induction of transgenic roots by poplar cuttings. This is in agreement with a systematic investigation of the usability of A. rhizogenes strains for plant root transformation by Porter and Flores (1991), who also stated strain K599 as being the most efficient. In contrast to hybrid poplars, we were not able to observe transgenic root formation on Populus trichocarpa cuttings, which is in agreement with many unsuccessful attempts of A. tumefaciens-based P. trichocarpa transformation (e.g., Böhlenius et al. 2006).

Sucrose containing agar medium is routinely used for rooting of poplar cuttings. Sucrose is, however, known a potent plant root morphogen (Freixes et al. 2002; LeeHo et al. 2007). As A. rhizogenes-based transformation frequently results in modulation of root phytohormone response, such a sugar effect might enhance the hairy root phenotype of composite plants. Indeed, sucrose containing agar medium increased root branching. However, this phenomenon was observed for both non-transgenic and transgenic roots and was not more pronounced in transgenic roots. As rooting of K599 inoculated plants was even a bit better without sucrose, we routinely omitted sucrose from the rooting medium.

Even when poplar transformation efficiency was in the range of other plants (Porter and Flores 1991), a distinct number of newly formed roots showed a slight hairy root phenotype but no fluorescent marker expression, indicating that the T-DNA of the binary vector was not transmitted together with the T-DNA of the Ri plasmid. If binary vector based T-DNA does not allow direct visualization of successful root transformation (e.g., in case of RNAi or overexpression approaches), examination of a much larger root number would be the consequence. A strategy to solve this problem is the additional integration of a visual marker cassette into the T-DNA region of the binary vector. Peroxisomal targeted fluorescent proteins (as used in this work) would be ideally suited as they allow an easy in planta detection of transgenic roots without severe disturbance of root physiology.

Peroxisomal targeted fluorescent proteins also helped to cure a general problem of poplar fine roots and in particular ectomycorrhizas: cell wall autofluorescence, which covers a wide emission range and hence cannot be simply eliminated technically. Rhizodermal and root cortical cells comprise large central vacuoles. As a consequence, the cytoplasmic layer has a thickness of about that of the cell wall, making detection of cytoplasm located fluorescent proteins rather difficult. In non-mycorrhized poplar roots (but not ectomycorrhizas), argon laser intensities below $2 \%$ eliminate the autofluorescence problem, but do request a strong specific fluorescence signal. Targeting of fluorescent proteins into peroxisomes leads to protein enrichment in small cellular compartments and thus strong fluorescence signal intensities. Peroxisomes are, furthermore, frequently found far away from cell walls, e.g., in cytoplasmic tubes crossing the central vacuole. In cases, where cell wall autofluorescence is still visible even at low laser intensities, e.g., in ectomycorrhizas, peroxisomes that are located in a given distance from the cell wall allow specific and highly sensitive fluorescence signal detection.

Every root formed by a composite plant could be the result of an independent transformation event (Costantino et al. 1983). Different copy numbers or positional effects of genome integrated T-DNAs (e.g., Collier et al. 2005) would result in varying gene expression levels in individual roots. Indeed, independent roots of single composite poplars showing differences in YFP fluorescence intensity were observed in this work (data not shown). However, the conventional transgenic plants also show such variation, resulting in the necessity to analyze a given number of independent transformants. Whether or not individual root transformation events limit composite plant application is depending on the question to be addressed. Based on fluorescent protein expression and microscopy, we successfully performed promoter analysis of ectomycorrhiza-induced genes with composite poplars (Nehls et al. unpublished). For such analysis, only minor amounts of roots/ectomycorrhizas are requested and analysis of single roots is feasible even in axenic culture (Petri dish system) with a limited amount of root material. For biochemical analysis, however, small root systems can be problematic. In such cases, transfer of plants into pot culture might be a solution to obtain sufficient root material. Pot culture is, however, hardly feasible under sterile conditions. An alternative strategy is thus pooling of root material of different plants prior to analysis. Of course, individual differences will be no longer recognized by this approach, but for many questions, e.g., assessment of the impact of a manipulation, an average picture is sufficient. We successfully followed this strategy for many years when pooling ectomycorrhizas from root systems of different plants prior to analysis. Individual ectomycorrhizas can be rather variable, e.g., in terms of sugar content (Nehls, unpublished). Batchwise analysis gives, however, similar results as analysis of individuals and calculation of means, if sufficient large numbers of mycorrhizas were used (Fajardo López et al. 2007; Nehls, unpublished).

Using the later strategy, we were able to compare ectomycorrhizal sugar content and marker gene expression in infected transgenic and non-transgenic fine roots. As fungal mycelia and plant root cells are inseparably linked in ectomycorrhizas, only organism-specific metabolites can be allocated to a given partner in symbiosis. With regard to sugars, sucrose (plant origin) and trehalose (fungus origin) fulfil this criterion. Whereas plants are capable in trehalose biosynthesis, this sugar is hardly detectable in plant tissues (Müller 
et al. 1999) and trehalose content of ectomycorrhizas is thus assumed to be solely of fungal origin (e.g., Fajardo López et al. 2007). While sucrose content was indistinguishably between ectomycorrhizas of non-transgenic and transgenic fine roots, trehalose content was slightly but significantly higher (24\%) in mycorrhizas of transgenic roots. This indicates that fungal sugar support is somewhat better in transgenic roots of composite poplars. Furthermore, transcript levels of polar PtaSWEET1 were also about 25\% higher in ectomycorrhizas of transgenic roots, which is in line with the elevated fungal trehalose content. SWEET proteins are characterized as sugar facilitators and are supposed to function as sugar efflux carriers in certain biotrophic interactions (Chen et al. 2010). In poplar ectomycorrhizas, distinct members of the SWEET gene family (e.g., PtaSWEET1) are induced in a symbiosis-specific manner and are thus supposed to be responsible for fungal sugar support (Nehls and Bodendiek 2012; Nehls, unpublished). Increased PtaSWEET1 transcript levels of composite poplar roots thus indicate elevated sugar efflux from root cells, resulting in better fungal carbon nutrition and, in a consequence, in increased trehalose content of ectomycorrhizal fungal mycelia.

The known consequence of Ri-plasmid-based T-DNA integration into the plant root genome is modulation in phytohormone (especially auxin) response (Christey 2001; Kiselev et al. 2007). As root transformation did not result in elevated PtaSWEETI transcript levels, such a variation in phytohormone response is not sufficient to control PtaSWEET1 expression. However, similar to A. rhizogenes-based root transformation, fungal hyphae manipulate root phytohormone content upon ectomycorrhizal symbiosis, which has been frequently discussed as a central mechanism for influencing plant root morphology and function (Nehls et al. 1998; Vayssières et al. 2015). A. rhizogenes T-DNA triggered improvement of fungal sugar support in symbiosis thus indicates a direct link between root auxin content/susceptibility and fine tuning of fungal carbon support and will be further addressed in upcoming research.

\section{Summary}

We have developed a protocol for generation of composite poplars that reduce the time demand for formation of transgenic plants from several months to a few weeks. While all investigated agrobacterial isolates were able to transform poplar roots, striking drawbacks were observed for three of them, making the strain K599 in our hands most suitable for poplar transformation. Transgenic root formation on non-transgenic, sterile cuttings was regularly induced. Such roots showed an only weak tendency for a hairy root phenotype but strong marker expression (fluorescence). In poplar fine roots but particularly in ectomycorrhizas, peroxisomal localization of the fluorescent signal leads to a sensitive in planta detection of gene expression and solves the problem of a broad cell wall autofluorescence. Finally, both fungal trehalose content and plant PtaSWEETI expression point towards elevated fungal carbon support in ectomycorrhizas of transgenic poplar fine roots.

Author contribution statement UN conceived and designed research and supervised $\mathrm{DN}, \mathrm{AD}$, and $\mathrm{AH}$. DN, $\mathrm{AD}, \mathrm{AH}$, and $\mathrm{UN}$ conducted experiments; $\mathrm{DN}, \mathrm{AD}$, and $\mathrm{UN}$ analyzed data. UN, DN, and AD wrote the manuscript. All authors read and approved the manuscript.

Acknowledgements We would like to thank Prof. Dr. R. Hänsch (TU-Braunschweig, Braunschweig 38106, Humboldstraße 1) for providing pBIN19-YFPPTS1, the Max Plank Institute for Marine Microbiology (Bremen) for the extensive access to their confocal Laser Scanning Microscope and in particular Andreas Ellrott for generous technical support. This work was financed by the German Science Foundation (Ne 332/14-1).

\section{Compliance with ethical standards}

Conflict of interest The authors declare that they have no conflict of interest.

Open Access This article is distributed under the terms of the Creative Commons Attribution 4.0 International License (http://creativecommons.org/licenses/by/4.0/), which permits unrestricted use, distribution, and reproduction in any medium, provided you give appropriate credit to the original author(s) and the source, provide a link to the Creative Commons license, and indicate if changes were made.

\section{References}

Alpizar E, Dechamp E, Espeout S, Royer M, Lecouls AC, Nicole M, Bertrand B, Lashermes P, Etienne H (2006) Efficient production of Agrobacterium rhizogenes-transformed roots and composite plants for studying gene expression in coffee roots. Plant Cell Rep 25:959-967

An GH (1985) High-efficiency transformation of cultured tobacco cells. Plant Physiol 79:568-570

Banerjee S, Singh S, Pandey P (2017) "Hairy Root" technology: an emerging arena for heterologous expression of biosynthetic pathway genes in medicinal plants. In: Jha S (ed) Transgenesis and secondary metabolism. Springer, Berlin, pp 295-322

Bevan M (1984) Binary Agrobacterium vectors for plant transformation. Nucleic Acids Res 12:8711-8721

Böhlenius H, Huang T, Charbonnel-Campaa L, Brunner AM, Jansson S, Strauss SH, Nilsson O (2006) CO/FT: regulatory module controls timing of flowering and seasonal growth cessation in trees. Science 312:1040-1043

Brunner AM, Yakovlev IA, Strauss SH (2004) Validating internal controls for quantitative plant gene expression studies. BMC Plant Biol 4:1-7 
Cardarelli M, Spanò L, Mariotti D, Mauro ML, Van Sluys MA, Costantino P (1987) The role of auxin in hairy root induction. Mol Gen Genet MGG 208:457-463

Chen L-Q, Hou B-H, Lalonde S, Takanaga H, Hartung ML, Qu X-Q, Guo W-J, Kim J-G, Underwood W, Chaudhuri B, Chermak D, Antony G, White FF, Somerville SC, Mudgett MB, Frommer WB (2010) Sugar transporters for intercellular exchange and nutrition of pathogens. Nature 468:527-532

Christey MC (2001) Invited review: use of Ri-mediated transformation for production of transgenic plants. In Vitro Cell Dev Plant 37:687-700

Collier R, Fuchs B, Walter N, Kevin Lutke W, Taylor CG (2005) Ex vitro composite plants: an inexpensive, rapid method for root biology. Plant J 43:449-457

Costantino P, Spano L, Pomponi M, Benvenuto E, Ancora G (1983) The T-DNA of Agrobacterium rhizogenes is transmitted through meiosis to the progeny of hairy root plants. J Mol Appl Genet 2:465-470

Daimon H, Fukami M, Mii M (1990) Hairy root formation in peanut by the wild type strains of Agrobacterium rhizogenes. Plant Tissue Cult Lett 7:31-34

Danielsen L, Lohaus G, Sirrenberg A, Karlovsky P, Bastien C, Pilate G, Polle A (2013) Ectomycorrhizal colonization and diversity in relation to tree biomass and nutrition in a plantation of transgenic poplars with modified lignin biosynthesis. PLoS One 8:e59207

Dobner I (2003) Der Einsatz mykorrhizierter Gehölze in biologischen Sanierungsverfahren unter dem Aspekt TNT-belasteter Böden, Dissertation. University of Bremen, Bremen

Ehlting B, Dluzniewska P, Dietrich H, Selle A, Teuber M, Hänsch R, Nehls U, Polle A, Schnitzler J-P, Rennenberg H, Gessler A (2007) Interaction of nitrogen nutrition and salinity in Grey poplar (Populus tremula $\times$ alba). Plant Cell Environ 30:796-811

Eom J-S, Chen L-Q, Sosso D, Julius BT, Lin IW, Qu X-Q, Braun DM, Frommer WB (2015) SWEETs, transporters for intracellular and intercellular sugar translocation. Curr Opin Plant Biol 25:53-62

Escalante-Pérez M, Lautner S, Nehls U, Selle A, Teuber M, Schnitzler JP, Teichmann T, Fayyaz P, Hartung W, Polle A, Fromm J, Hedrich R, Ache P (2008) Salt stress affects xylem differentiation of grey poplar (Populus $\times$ canescens). Planta 229:299-309

Fajardo López M, Männer P, Willmann A, Hampp R, Nehls U (2007) Increased trehalose biosynthesis in Hartig net hyphae of ectomycorrhizas. New Phytol 174:389-398

Freixes S, Thibaud MC, Tardieu F, Muller B (2002) Root elongation and branching is related to local hexose concentration in Arabidopsis thaliana seedlings. Plant Cell Environ 25:1357-1366

Hampp R, Schaeffer C, Wallenda T, Stülten C, Johann P, Einig W (1995) Changes in carbon partitioning or allocation due to ectomycorrhiza formation: biochemical evidence. Can J Bot 73:548-556

Hampp R, Ecke M, Schaeffer C, Wallenda T, Wingler A, Kottke I, Sundberg B (1996) Axenic mycorrhization of wild type and transgenic hybrid aspen expressing T-DNA indoleacetic acid-biosynthetic genes. Trees 11:59-64

Hampp R, Nehls U, Wallenda T (2000) Physiology of mycorrhiza. In: Lüttge U (ed) Progress in botany. Springer, Berlin, pp 223-254

Hansen J, Jorgensen JE, Stougaard J, Marcker KA (1989) Hairy rootsa short cut to transgenic root-nodules. Plant Cell Rep 8:12-15

Hansen G, Larribe M, Vaubert D, Tempe J, Biermann BJ, Montoya AL, Chilton M-D, Brevet J (1991) Agrobacterium rhizogenes pRi8196 T-DNA: mapping and DNA sequence of functions involved in mannopine synthesis and hairy root differentiation. PNAS 88:7763-7767

Hellens RP, Edwards EA, Leyland NR, Bean S, Mullineaux PM (2000) pGreen: a versatile and flexible binary Ti vector for Agrobacterium-mediated plant transformation. Plant Mol Biol 42:819-832
Hirsch S, Kim J, Muñoz A, Heckmann AB, Downie JA, Oldroyd GE (2009) GRAS proteins form a DNA binding complex to induce gene expression during nodulation signaling in Medicago truncatula. Plant Cell 21:545-557

Holsters M, de Waele D, Depicker A, Messens E, van Montagu M, Schell J (1978) Transfection and transformation of Agrobacterium tumefaciens. Mol Gen Genet 163:181-187

Kereszt A, Li D, Indrasumunar A, Nguyen CD, Nontachaiyapoom S, Kinkema M, Gresshoff PM (2007) Agrobacterium rhizogenesmediated transformation of soybean to study root biology. Nat Protoc 2:948

Kim HJ, Murai N, Fang DD, Triplett BA (2011) Functional analysis of Gossypium hirsutum cellulose synthase catalytic subunit 4 promoter in transgenic Arabidopsis and cotton tissues. Plant Sci 180:323-332

Kiselev K, Dubrovina A, Veselova M, Bulgakov V, Fedoreyev S, Zhuravlev YN (2007) The rolB gene-induced overproduction of resveratrol in Vitis amurensis transformed cells. J Biotechnol 128:681-692

Kottke I, Guttenberger M, Hampp R, Oberwinkler F (1987) An in vitro method for establishing mycorrhizae on coniferous tree seedlings. Trees 1:191-194

Langer K, Levchenko V, Fromm J, Geiger D, Steinmeyer R, Lautner S, Ache P, Hedrich R (2004) The poplar $\mathrm{K}^{+}$channel KPT1 is associated with $\mathrm{K}^{+}$uptake during stomatal opening and bud development. Plant J 37:828-838

Lee-Ho E, Walton LJ, Reid DM, Yeung EC, Kurepin LV (2007) Effects of elevated carbon dioxide and sucrose concentrations on Arabidopsis thaliana root architecture and anatomy. Can J Bot 85:324-330

Lloyd G, McCown BH (1980) Commercially-feasible micropropagation of mountain laurel, Kalmia latifolia, by use of shoot-tip culture. Int Plant Propag Soc Proc 30:421-427

Mankin SL, Hill DS, Olhoft PM, Toren E, Wenck AR, Nea L, Xing L, Brown JA, Fu H, Ireland L, Jia H, Hillebrand H, Jones T, Song H-S (2007) Disarming and sequencing of Agrobacterium rhizogenes strain K599 (NCPPB2659) plasmid pRi2659. In Vitro Cell Dev Biol Plant 43:521-535

Mrosk C, Forner S, Hause G, Küster H, Kopka J, Hause B (2009) Composite Medicago truncatula plants harbouring Agrobacterium rhizogenes-transformed roots reveal normal mycorrhization by Glomus intraradices. J Exp Bot 60:3797-3807

Müller J, Wiemken A, Aeschbacher R (1999) Trehalose metabolism in sugar sensing and plant development. Plant Sci 147:37-47

Murashige T, Skoog F (1962) A revised medium for rapid growth and bio assays with tobacco tissue cultures. Physiol Plant 15:473-497

Nehls U, Bodendiek I (2012) Carbohydrates exchange between symbionts in ectomycorrhizas. In: Hock B (ed) Fungal associations. Springer, Berlin, pp 119-136

Nehls U, Beguiristain T, Ditengou F, Lapeyrie F, Martin F (1998) The expression of a symbiosis-regulated gene in eucalypt roots is regulated by auxins and hypaphorine, the tryptophan betaine of the ectomycorrhizal basidiomycete Pisolithus tinctorius. Planta 207:296-302

Nowak K, Luniak N, Meyer S, Schulze J, Mendel RR, Hansch R (2004) Fluorescent proteins in poplar: a useful tool to study promoter function and protein localization. Plant Biol (Stuttg) 6:65-73

Ohmiya Y, Nakai T, Park YW, Aoyama T, Oka A, Sakai F, Hayashi T (2003) The role of PopCel1 and PopCel2 in poplar leaf growth and cellulose biosynthesis. Plant J 33:1087-1097

Park J-Y, Canam T, Kang K-Y, Unda F, Mansfield SD (2009) Sucrose phosphate synthase expression influences poplar phenology. Tree Physiol 29:937-946

Porter JR, Flores H (1991) Host range and implications of plant infection by Agrobacterium rhizogenes. Crit Rev Plant Sci 10:387-421 
Ron M, Kajala K, Pauluzzi G, Wang D, Reynoso MA, Zumstein K, Garcha J, Winte S, Masson H, Inagaki S, Federici F, Sinha N, Deal RB, Bailey-Serres J, Brady SM (2014) Hairy root transformation using Agrobacterium rhizogenes as a tool for exploring cell type-specific gene expression and function using tomato as a model. Plant Physiol 166:455-469

Selle A, Willmann M, Grunze N, Geßler A, Weiß M, Nehls U (2005) The high-affinity poplar ammonium importer PttAMT1.2 and its role in ectomycorrhizal symbiosis. New Phytol 168:697-706

Shiomi T, Shirakawa T, Takeuchi S, Oizumi T, Uematsu S (1987) Hairy root of melon caused by Agrobacterium rhizogenes biovar 1. Annals of the Phytopathological Society of Japan, Japan

Smith S, Read D (2008) Mycorrhizal symbiosis. Academic Press, London

Srivastava S, Srivastava AK (2007) Hairy root culture for mass-production of high-value secondary metabolites. Crit Rev Biotechnol 27:29-43

Stefani FOP, Moncalvo J-M, Seguin A, Berube JA, Hamelin RC (2009) Impact of an 8-year-old transgenic poplar plantation on the ectomycorrhizal fungal community. Appl Environ Microbiol 75:7527-7536

Vayssières A, Pěnčík A, Felten J, Kohler A, Ljung K, Martin F, Legué V (2015) Development of the poplar-Laccaria bicolor ectomycorrhiza modifies root auxin metabolism, signaling, and response. Plant Physiol 169:890-902

Veena V, Taylor CG (2007) Agrobacterium rhizogenes: recent developments and promising applications. In Vitro Cell Dev Plant 43:383-403

Willmann A, Thomfohrde S, Haensch R, Nehls U (2014) The poplar NRT2 gene family of high affinity nitrate importers: impact of nitrogen nutrition and ectomycorrhiza formation. Environ Exp Bot 108:79-88

Wubben MJ, Callahan FE, Triplett BA, Jenkins JN (2009) Phenotypic and molecular evaluation of cotton hairy roots as a model system for studying nematode resistance. Plant Cell Rep 28:1399-1409

Zhang C, Han L, Slewinski TL, Sun J, Zhang J, Wang Z-Y, Turgeon R (2014) Symplastic phloem loading in poplar. Plant Physiol 166:306-313 